\title{
Keratoacanthoma in the cutaneous area of the upper lip: A case report
}

\section{Ceratoacantoma em região cutânea de lábio superior: Relato de caso}

\begin{abstract}
Purpose: The aim of this paper is to briefly review and discuss the literature about KA and present a case report with a 2-year follow-up of the removal of a KA lesion in the upper lip.

Case description: A 53-year-old woman complained of a painless, aesthetically unpleasant brownish, hard lesion in the cutaneous area of the upper lip. The lesion had grown rapidly in the last 30 days (size: $\sim 10 \times 5 \mathrm{~mm}$ ), and was associated with a hot waxing hair removal. Surgical excision was the treatment chosen in order to differentiate the lesion from squamous cell carcinoma (SCC). An oval-shaped incision was created with an in-depth wedge shape for the removal of the lesion and better approximation of the edges after synthesis. Histopathological analysis confirmed the diagnosis of KA. After 2 years, the patient was completely satisfied with the treatment, and no scar was evident.

Conclusion: Due to the clinical difficulty in differentiating KA from SCC and the risk for formation of an aesthetically unpleasant scar upon spontaneous resolution of KA, surgical removal might be considered the treatment of choice for a solitary KA.
\end{abstract}

Key words: Hair follicle; keratoacanthoma; keratins

\section{Resumo}

Objetivo: $O$ objetivo deste trabalho é revisar e discutir brevemente a literatura sobre CA e apresentar o relato de um caso da remoção de CA em lábio superior com 2 anos de acompanhamento.

Descrição do caso: Mulher com 53 anos queixava-se de lesão indolor, esteticamente desagradável, dura e de coloração marrom na área cutânea do lábio superior. A lesão havia crescido rapidamente nos últimos 30 dias (tamanho: $\sim 10 \times 5 \mathrm{~mm}$ ), e estava associada à remoção de pêlos com cera quente. Excisão cirúrgica foi o tratamento escolhido para diferenciar a lesão de carcinoma espinocelular (CEC). Uma incisão em forma oval aprofundada em forma de cunha foi realizada para remoção da lesão e melhor aproximação das bordas após a síntese. A análise histopatológica confirmou o diagnóstico de CA. Após 2 anos, a paciente estava completamente satisfeita com o tratamento, e nenhuma cicatriz era evidente. Conclusão: Devido à dificuldade na diferenciação clínica entre CA e CEC, e o risco de formação de cicatriz esteticamente desagradável quando da resolução espontânea do $C A$, a remoção cirúrgica pode ser considerada o tratamento de escolha para CA solitário.

Palavras-chave: Folículo piloso; ceratoacantoma; ceratinas

\author{
Heloisa Har Machado ${ }^{\circ}$ \\ Alessandro Menna Alves" \\ Ana Paula Neutzling Gomes a \\ Marcos Antonio Torriani a
}

a School of Dentistry, Federal University of Pelotas, Pelotas, RS, Brazil
Correspondence:

Heloisa Har Machado

Rua Gonçalves Chaves 457

School of Dentistry, UFPel

Pelotas, RS - Brasil

96015-560

E-mail: heloisa.machado86@gmail.com

Received: February 6, 2012

Accepted: August 8, 2012

Conflict of Interests: The authors state that there are no financial and personal conflicts of interest that could have inappropriately influenced their work.

Copyright: (C) 2012 Machado et al.; licensee EDIPUCRS. This is an Open Access article distributed under the terms of the Creative Commons AttributionNoncommercial-No Derivative Works 3.0 Unported License. 


\section{Introduction}

Keratoacanthoma (KA) is a common benign skin lesion composed of keratinized squamous cells that originates in the hair follicle. The clinical and histopathological features of KA are similar to squamous cell carcinoma (SCC) of the skin, which often complicates a differential diagnosis (1). KA usually appears as a skin-colored papule with a central keratin core similar to a "volcano": it grows for a period of 2 to 4 weeks, reaching up to $2 \mathrm{~cm}$ at its largest. The tumor usually appears on sun-exposed areas in middle-aged or older patients, which suggests an etiological association with ultraviolet light exposure (1). Other factors that may contribute to the development of KAs are genetic factors, immunosuppression, potentially carcinogenic chemicals, viruses, and trauma (2).

Clinically, KA may appear as a sporadic solitary lesion or as multiple lesions associated with hereditary syndromes. KAs can be associated with a condition called Muir-Torre syndrome, which involves multiple sebaceous neoplasms and internal malignancies such as colon cancer; in such a situation, KA may be present in anybody region $(3,4)$. The solitary type of KA has a typically rapid development, growing in areas that are exposed to the sun and tending to resolve spontaneously within 6 months (5). In most cases of spontaneous regression, however, formation of an aesthetically unpleasant scar is observed (5). The recurrence of KA is unusual, being reported around 3-5\% of the time (6).

There is no report in the literature regarding the development of KA associated with hot waxing hair removal. This procedure, which is popular among women, may traumatize the epithelium and contribute to the etiology of skin lesions. The aim of this paper is to briefly review and discuss the literature about KA and present a case report with a 2-year follow-up of the removal of a KA lesion in the cutaneous area of the upper lip associated with a hot waxing hair removal.

\section{Case Description}

A 53-year-old Caucasian woman sought treatment at the outpatient dental clinic at Federal University of Pelotas (UFPel), Pelotas, RS, Brazil, complaining of a painless, aesthetically unpleasant brownish lesion in the cutaneous area of the upper lip. As shown in Figure 1, the lesion was hard, approximately $10 \times 5 \mathrm{~mm}$ in size, and had a sessile base. During the interview, the patient reported that she had first noticed the lesion about 30 days before that, and that the tumor had grown rapidly to its current size. Before the appearance of the lesion, the patient had undergone a hot waxing hair removal in the area, resulting in excoriation. At the end of the clinical investigation, surgical excision of the lesion was the treatment chosen. The initial clinical diagnosis was KA, but there was a need to differentiate it from SCC.

Initially, local antisepsis with polyvinyl pyrrolidone iodine in aqueous solution was carried out to avoid contamination of the surgical wound by skin microorganisms. Anesthesia was induced by infiltration of $2 \%$ lidocaine hydrochloride with epinephrine around the lesion. An Adson forceps with teeth was used to contain the lesion and thumb compression was applied to the lip to reduce bleeding. An oval-shaped incision was created using a \#15 scalpel blade, with an indepth wedge shape for the removal of the lesion and better approximation of the lesion edges after the synthesis (Fig. 2). Suturing was performed using 5-0 nylon (Fig. 3).

The surgical piece was fixed in 10\% formalin and sent to the Center of Diagnosis of Oral Diseases (CDDB), School of Dentistry/UFPel, for histopathological analysis and confirmation of the diagnosis (Fig. 4). The recommendations given to the patient were the same general guidelines for regular surgical biopsies in dentistry, emphasizing the importance of suture removal after 7 days and taking care of the region during sun exposure to avoid formation of an aesthetically unpleasant scar.

The histologic analysis in light microscopy of sections stained with hematoxylin and eosin (Fig. 5) revealed an orthokeratinized stratified squamous epithelium (asterisk), which invaginated into the conjunctive tissue from the lateral margins, generating a whole conical appearance with the center filled with a large amount of keratin (arrow). The epithelium that infiltrated the conjunctive tissue showed hyperplasia, mild nuclear atypia, and pronounced dyskeratosis. Mononuclear inflammatory infiltrate was found together with the epithelium; in addition to the presence of regular skin appendages, this completed the histological picture of KA.

At the time of suture removal, the patient received the histopathological report. In the clinical observation of the area one month after the biopsy, little evidence of the incision was observed. The patient was advised to take care during sun exposure for at least 90 days by protecting the area with microporous tape. After 2 years, no scar was evident (Fig. 6) and the patient was completely satisfied with the treatment.

\section{Discussion}

The cause of KAs is still uncertain, although some studies $(2,5)$ show their appearance in areas that had been previously traumatized, which was true in the present case. Besides the relationship between KA and the regions exposed to ultraviolet rays, some studies reported higher observation of KA in leucoderma patients and lower observation of KA in melanoderma patients $(7,8)$. There is a report (1) of KAs in healthy skin edges after surgical excision of other lesions such as SCC and lentigo maligna. These lesions were initially diagnosed as a recurrence of the original lesion; however, upon examination, the diagnosis of KA was confirmed (1).

$\mathrm{KA}$ is also known as a self-healing cancer because it undergoes spontaneous regression in most cases, often leaving an unpleasant cosmetic result. The spontaneous regression takes up to 6 months, requiring the patient to endure the unaesthetic injury for a long period until its total disappearance. Griffiths (9) proposed to observe the lesion with photographic documentation at each visit, with follow-ups every 15 days or so. However, lesions in immunocompromised patients show no signs of regression 


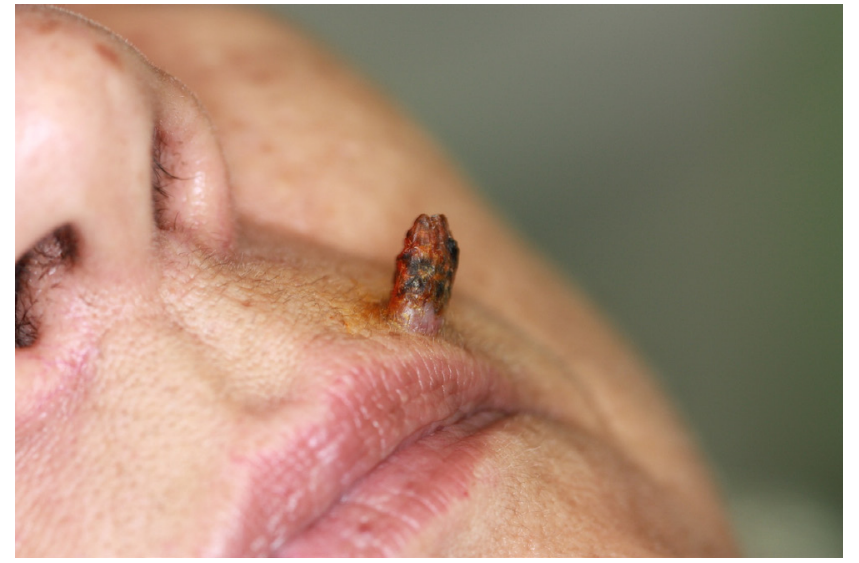

Fig. 1. Preoperative appearance of the lesion with 30 days of evolution.

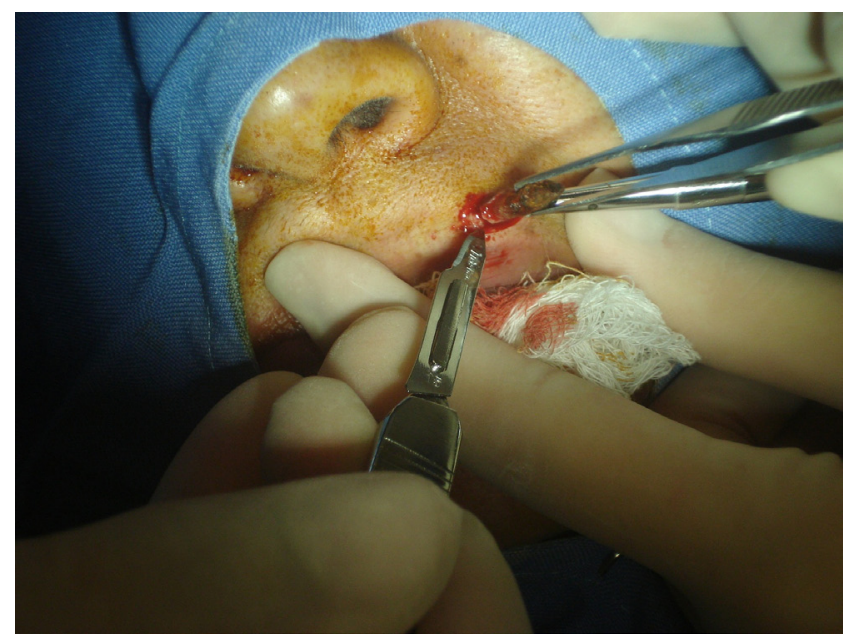

Fig. 2. Oval-shaped incision with an in-depth wedge shape for the removal of the lesion and better approximation of the lesion edges after synthesis.

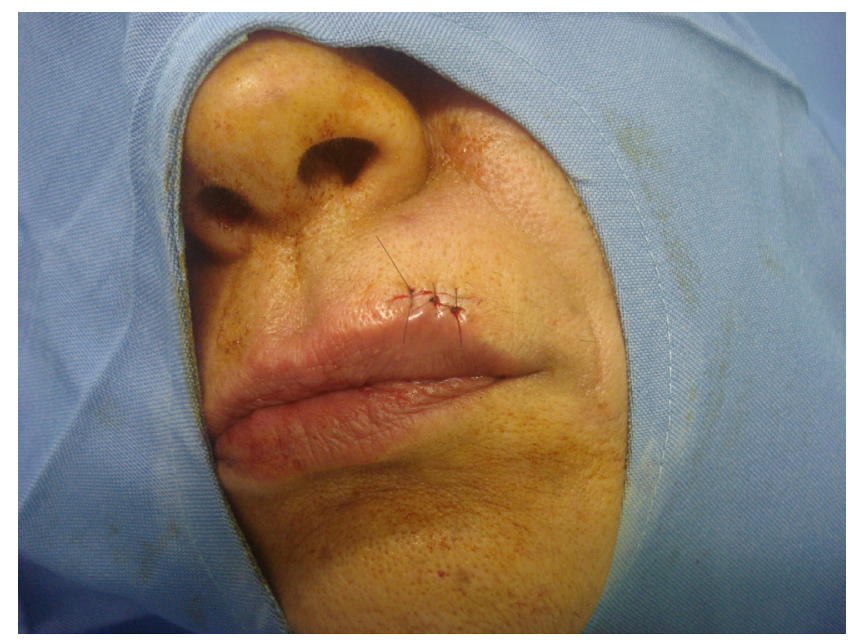

Fig. 3. Suture with 5-0 nylon.

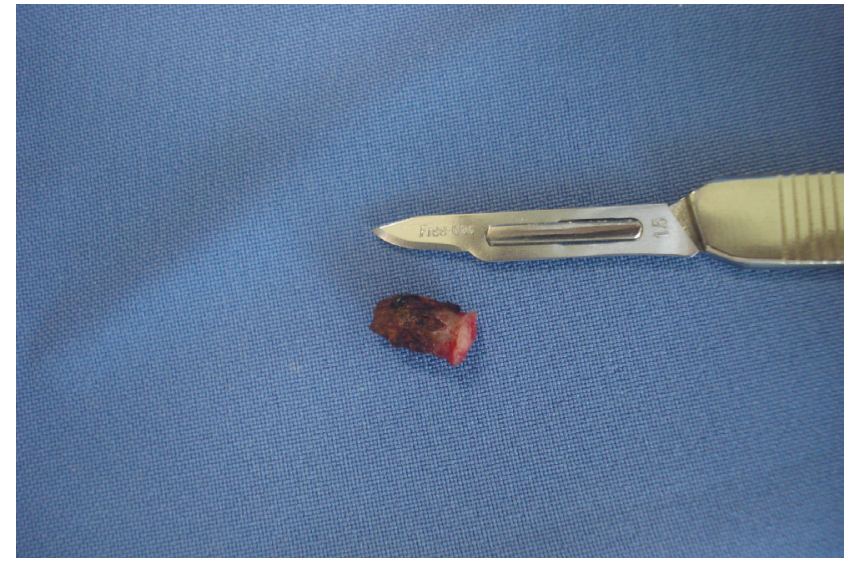

Fig. 4. Surgical piece from the excisional biopsy sent for histopathological analysis.

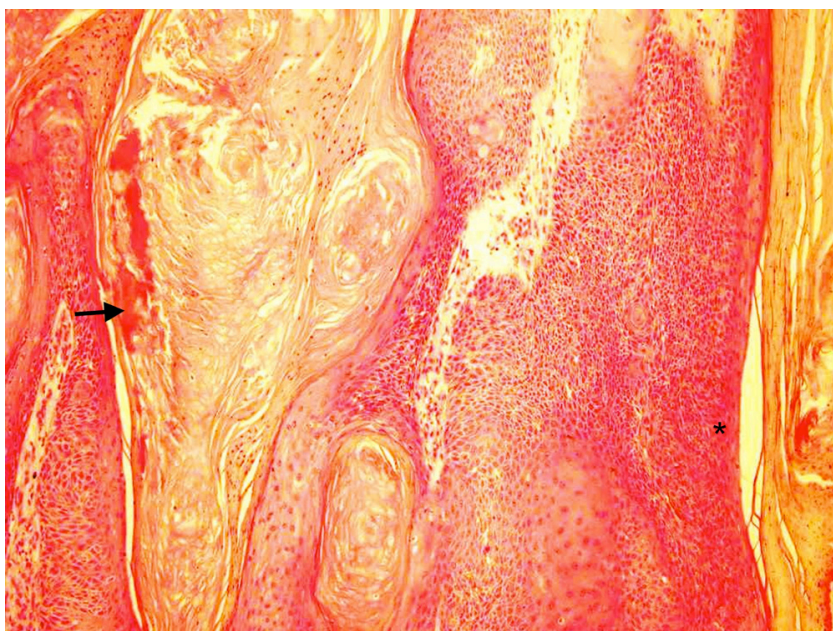

Fig. 5. Histological section (x100) showing an orthokeratinized stratified squamous epithelium (asterisk), which invaginated into the conjuctive tissue from the lateral margins, generating a whole conical appearance with the center filled with keratin (arrow).

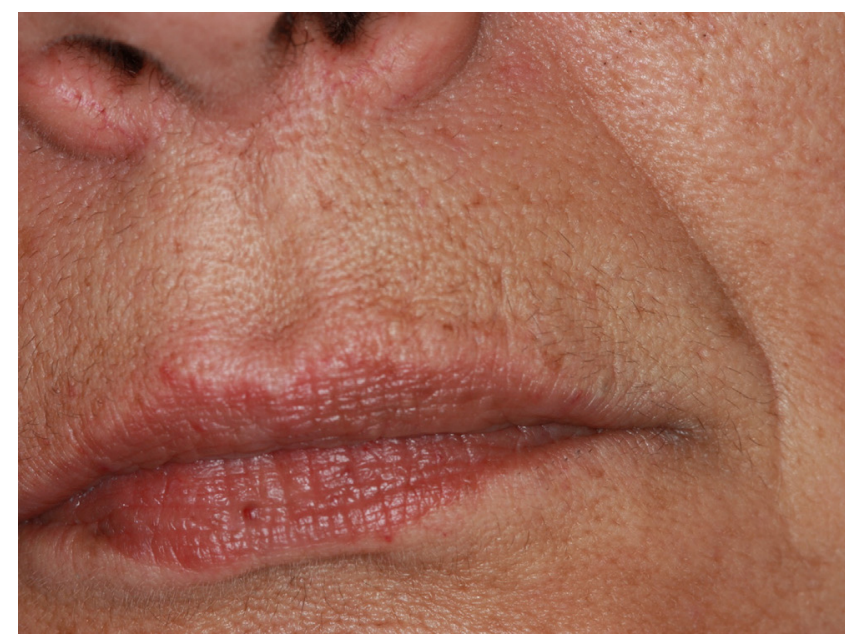

Fig. 6. Postoperative appearance of the area after 2 years. 
after 4 to 6 weeks; also, when there is doubt in the diagnosis between SCC and KA, surgical excision is necessary (9).

It has been reported that $\sim 5 \%$ of oncologic patients develop metastatic skin lesions (13), which are rarely diagnosed as KAs; less than $1 \%$ of the patients show skin lesions as a first metastatic sign of their visceral cancer (13). Although KA can be considered a well-differentiated SCC (10), this condition is usually considered only when KA undergoes malignant transformation (with presence of areas of SCC), which has been reported to occur in $\sim 25 \%$ of cases (11). Corbálan-Vélez et al. (11) indicated immunohistochemical staining for laminin-322 as useful for distinguishing between KA, KA with areas of SCC, and SCC.

Muir-Torre syndrome should be investigated in patients with KA lesions by family research, clinical presence of other tumors of sebaceous glands, or presence of adenomatous polyps of the colon. In the case here reported, the clinical conditions excluded the possibility of Muir-Torre syndrome; however, for patients with at least one sebaceous neoplasm or an internal malignant neoplasm (e.g. colorectal cancer), mutation analysis of the genes involved is required to complete the diagnosis (12).

In some cases in the literature on treatment of KAs, as in the case reported by Ramos et al. (14), the option is to remove a small portion of the lesion, including healthy skin and vermilion of the lip. This option would allow histopathological analysis and exclusion of the possibility of a neoplastic lesion with aggressive growth potential. Yet, the incisional biopsy may trigger the onset of regression of the lesion, probably due to the inflammatory changes that occur after surgery (14).

Due to the aesthetic discomfort that the patient complained in the present case, we opted for excisional biopsy rather than follow-up, since the procedure was simple and would reduce the risk of a cosmetically unfavorable scar resulting from spontaneous resolution. In addition, the patient reported no previous formation of keloids or hypertrophic scars, opting for the surgical excision of the lesion. The surgical procedure also aided in eliminating the patient's anxiety and discomfort caused by the lesion $(1,15)$. After 2 years, no scar was evident.

Despite the tendency of KA to spontaneously resolve, which indicates a benign course, it is known that KAs occasionally have tissue destructive and metastatic potential, with the infiltrative growth causing pain. In such a case, the clinical diagnosis differentiation between KA and well-differentiated SCC is difficult $(5,16)$. In addition, KA might also be considered a subtype of malignant lesion that should be treated accordingly (13). We share this view and, therefore, we consider surgical removal the treatment of choice for a solitary KA.

Due to the clinical difficulty in differentiating KA from SCC and the risk for formation of an aesthetically unpleasant scar upon spontaneous resolution of KA, surgical removal might be considered the treatment of choice for a solitary KA.

\section{References}

1. Karaa A, Khachemoune A. Keratoacanthoma: a tumor in search of a classification. Int J Dermatol 2007;46:671-8.

2. Pattee SF, Silvis NG. Keratoacanthoma developing in sites of previous trauma: a report of two cases and review of the literature. J Am Acad Dermatol 2003;48:S35-8.

3. Todd MM, Ammirati CT, Billingsley EM, Miller JJ, Helm KF. Multiple hyperkeratotic nodules on the arms. Arch Dermatol 2003;139:1363-8.

4. Feldman RJ, Maize JC. Multiple keratoacanthomas in a young woman: report of a case emphasizing medical management and a review of the spectrum of multiple keratoacanthomas. Int J Dermatol 2007;46:77-9.

5. Ko CJ. Keratoacanthoma: facts and controversies. Clin Dermatol 2010;28:254-61.

6. Kingman J, Callen JP. Keratoacanthoma. A clinical study. Arch Dermatol 1984;120:736-40.

7. Schwartz RA. Keratoacanthoma: a clinico-pathologic enigma. Dermatol Surg 2004;30:326-33.

8. Dogliotti M, Caro I. Keratoacanthoma in a Bantu child. Int J Dermatol 1976;15:524.

9. Griffiths RW. Keratoacanthoma observed. Br J Plast Surg 2004;57:485-501.

10. Beham A, Regaver S, Soyer HP, Beham-Schmid C. Keratoacanthoma: a clinically distinct variant of well differentiated squamous cell carcinoma. Adv Anat Pathol 1998;5:269-80.

11. Corbalán-Vélez R, Martínez-Barba E, López-Poveda MJ, Abarca-Gutiérrez IV, Ruíz-Maciá JA, Oviedo-Ramirez I, et al. The value of laminin-322 staining in distinguishing between keratoacanthoma, keratoacanthoma with areas of squamous cell carcinoma, and crateriform squamous cell carcinoma. Actas Dermosifiliogr 2012;103:308-16.

12. Mangold E, Pagenstecher C, Leister M, Mathiak M, Rutten A, Friedl W, et al. A genotypephenotype correlation in HNPCC: strong predominance of msh2 mutations in 41 patients with Muir-Torre syndrome. J Med Genet 2004;41:567-72.

13. Riahi RR, Cohen PR. Clinical manifestations of cutaneous metastases: a review with special emphasis on cutaneous metastases mimicking keratoacanthoma. Am J Clin Dermatol 2012;13:103-12.

14. Ramos LM, Cardoso SV, Loyola AM, Rocha MA, Durighetto-Junior AF. Keratoacanthoma of the inferior lip: review and report of case with spontaneous regression. J Appl Oral Sci $2009 ; 17: 262-5$

15. Schwartz RA. Keratoacanthoma. J Am Acad Dermatol 1994;30:1 - 19.

16. Tas E, Birol Ugur M, Gul A, Cinar F, Uzun L, Dogan Gun B. A misdiagnosed keratoacanthoma turned out to be a metastatic parotid carcinoma. Acta Otorhinolaryngol Ital 2010;30:1 15-7. 